\title{
Production of Zero Waste Biodiesel by Utilizing By-Products Glycerin and Biomass
}

\author{
Somesh M U ${ }^{1}$, Usha N Murthy ${ }^{2}$ \\ ${ }^{1}$ Research Scholar, Department of Civil Engineering, GMIT, Bharathinagara.. \\ ${ }^{2}$ Former Chairman \& Professor, Department of Civil Engineering, UVCE, JB Campus, Bangalore.
}

\begin{abstract}
Biodiesel is a popular alternative fuel. It is carbon neutral, has emissions equivalent to or below diesel, is biodegradable, non-toxic, and is significantly cheaper to manufacture than its petroleum equivalent. Biodiesel production creates glycerin as a byproduct. Although glycerin does have its commercial uses, even the current modest biodiesel production has outstripped glycerin demand. In this experiment the excess waste glycerin is combined with waste biomass to produce combustible pellets as an alternative to coal for energy production. The raw materials (waste glycerin and waste biomass) are mixed by weight ratio and blended by hand in a large mixing bowl. Various ratios of glycerin $(38.5 \mathrm{~g}$ and $31.3 \mathrm{~g})$ to waste biomass $(50 \mathrm{~g})$ were then mixed to produce a crude unfinished material. Initial results proved worthwhile, coming in at 15.4, 15.6, and $15.2 \mathrm{~kJ} / \mathrm{g}$ and displaying a respectable error rate of only $10 \%$ for ad-hoc apparatus. The Glycerin/Sawdust pellets produced an energy yield of $\approx \mathbf{1 6}$ $\mathrm{kJ} / \mathrm{g}$, placing their energy content within the expected range for existing fuel pellet infrastructure. The pellets can be viably manufactured using simple manufacturing equipment, and can be combusted as fuel in existing fuel pellet and Coal burning facilities. This will greatly facilitate pellet production and adoption as an alternative fuel source in increasingly resource-conscious world.
\end{abstract}

Key Words: Biodiesel, Glycerin, Biomass, Pellets.

\section{INTRODUCTION}

Biodiesel alludes to a vegetable oil-or creature fat-based diesel fuel comprising of long-chain alkyl (methyl, propyl or ethyl) esters. Biodiesel can be created from straight vegetable oil, creature oil/fats, fat and waste cooking oil. The procedure used to change over these oils to Biodiesel is called transesterification. Manure generation isn't the main source of pollution-related to the creation of biodiesel, different sources incorporate the esterification procedure, the dissolvable extraction of the oil, refining, drying and transporting.

However there is one significant drawback: for every 10 gallons of biodiesel produced, roughly 1 gallon of glycerin is created as a byproduct. Although glycerin does have its industrial uses, current biodiesel production has already exceeded market demand, leaving large amounts of practically worthless glycerin in the manufacturers' hands, leading to increased disposal costs. We show that by combining waste glycerin with waste biomass (corn husks, wheat chafe, etc.), we are able to produce pellets which can be easily and inexpensively manufactured, are suitable for existing combustion energy plants, and are a superior alternative to coal.

\section{METHODOLOGY}

The methodologies and processes used to produce biodiesel from used cooking are discussed below.

\subsection{Finding FFA Content (\%)}

- $\quad$ Method Used - Titration

- Reagents Used:

- $\quad$ Burette - 0.1N KOH solution

- Conical Flask - $10 \mathrm{ml}$ Isopropyl Alcohol, $1 \mathrm{ml}$ used cooking oil sample and 2 drops of phenolphthalein indicator.

- $\quad$ End point - Colorless to pale pink.

- The volume of $\mathrm{KOH}$ run down in burette gives the FFA concentration (\%). Source - Manual of Methods of Analysis of Foods, FSSAI, 2015.

\subsection{Transesterification Process \\ a. Method Used - Magnetic stirrer method \\ b. Laboratory equipment used - Magnetic stirrer} with hot plate, Erlenmeyer flasks/ conical flasks, funnels, sepratory funnel, beakers and thermometer.

c. Procedure: Calculated amount of catalyst \% (0.75, 1.0, 1.5 and 2.0) and alcohol (in molar ratios of 5:1 to 9:1) are mixed together in an Erlenmeyer flask until all the catalyst has dissolved in the alcohol. In the meantime, required amount of used cooking oil is heated to $60^{\circ} \mathrm{C}$ for a Methanol based reaction and $70^{\circ} \mathrm{C}$ for an Ethanol based reaction on the hot plate. The catalyst and alcohol mixture is gradually added to the oil and stirring is started. The desired reaction parameters are maintained and stirring is continued for 90 and 120 minutes for Methanol and Ethanol based reactions respectively. Then, the mixture is transferred into the separator funnel and allowed to settle down for 12 hours. Two distinct layers are formed in the separator funnel. The top layer is the biodiesel and the bottom layer is the by-product (glycerin and excess catalyst). Both these layers are collected into two separate beakers/ conical flasks whose empty weights are known. The product and by-product in the beakers areweighed and their respective weights are noted down. Then, the biodiesel yield is calculated.

\section{$2.3 \quad$ Glycerin-Biomass Pellets}

Biodiesel is a popular alternative fuel. It is carbon neutral, has emissions equivalent to or below diesel, is biodegradable, non-toxic, and is significantly cheaper to manufacture than its petroleum equivalent. However, there is one significant drawback: for every 10 gallons of biodiesel produced, roughly 1 gallon of glycerin is created as a byproduct. Although glycerin does have its industrial 
uses, current biodiesel production has already exceeded market demand, leaving large amounts of practically worthless glycerin in the manufacturers' hands, leading to increased disposal costs. By combining waste glycerin with waste biomass (corn husks, wheat chafe, saw dust, etc.), it is possible to produce pellets which can be easily and inexpensively manufactured, are suitable for existing combustion energy plants, and are a superior alternative to coal.

The energy values for glycerin waste pellets and competing energy sources are similar, showing that theoretically and experimentally, the glycerin waste pellet is a very suitable source in replacing or supplementing low end coal and refuse derived fuels.

The creation of waste pellets is already a significant industry in the developed world, converting waste from material and food industries to create compressed pellets suitable for combustion as an energy source. The manufacture of a pellet is easy to automate. In addition, the process often does not require heat input or a chemical change, and as such can be manufactured quickly. These manufactured pellets are called refuse derived fuels, or RDFs shown in Figure 2.3.1, and are primarily combusted within power plants and industrial boilers for energy purposes.

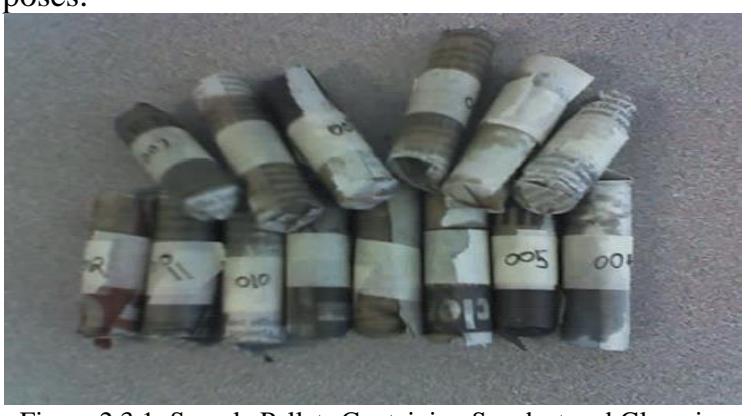

Figure 2.3.1: Sample Pellets Containing Sawdust and Glycerin.

Considering the vast array of materials already being formed into RDF and the ever-increasing demands for energy, there is plenty of scope in the market for an additional source. Pellet formation is fairly straight forward. The raw materials (waste glycerin and waste biomass - saw dust) are mixed by weight ratio (Glycerin 1:1.6 Sawdust) and blended by hand in a mixing bowl. The pellet mixture (approximately 12g) is placed inside a rolled piece of newspaper wrapping, and the ends are folded down so that both ends of the cylinder are covered.

This raw pellet is transferred into a mold, a short length of PVC with one end closed temporarily. The diameter of the PVC pipe is $12.5 \mathrm{~mm}$, and its length is four inches. The mold helps the pellet retain its cylindrical shape while a short metal rod, slightly smaller than the PVC pipe's internal diameter, is inserted into the open end of the mold to compress the pellet. Pressure was applied by hand, approximately 30 seconds. This pressure not only reduced the pellet size, but also encouraged the glycerin to permeate the materials and form a single firm unit.

\subsection{Refuse Derived Fuels (Rdf)}

The creation of waste pellets is already a significant industry in the developed world, converting waste from material and food industries to create compressed pellets suitable for combustion as an energy source. The manufacture of a pellet is easy to automate. In addition, the process often does not require heat input or a chemical change, and as such can be manufactured quickly. Many of these pellets are used in combustion plants, and therefore do not need extremely costly food-grade processing. These manufactured pellets are called refuse derived fuels, or RDFs shown in Figure 3, and are primarily combusted within power plants for energy purposes. Considering the vast array of materials already being formed into RDF and the ever-increasing demands for energy, there is plenty of room in the market for an additional source.

\section{$2.4 \quad$ Project/Design Approach}

Pellet formation is fairly straight forward. The raw materials (waste glycerin and waste biomass) are mixed by weight ratio and blended by hand in a large mixing bowl. Various ratios of glycerin $(38.5 \mathrm{~g}$ and $31.3 \mathrm{~g}$ ) to waste biomass $(50 \mathrm{~g})$ were then mixed to produce a crude unfinished material. The pellet mixture (approximately $12 \mathrm{~g}$ ) is placed inside a rolled piece of newspaper wrapping, and the ends are folded down so that both ends of the cylinder are covered. No adhesive is used, and until the pellet is compressed this unit will remain prone to unwrapping. Thisraw pellet is transferred into the mold, a short length of PVC with one end sealed. The diameter of the PVC pipe is $12.5 \mathrm{~mm}$, and its length is four inches. The mold helps the pellet retain its cylindrical shape while a short metal rod, slightly smaller than the PVC internal diameter, is inserted into the open end of the mold to compress the pellet. Pressure was applied by hand, approximately 250 psi for 15 seconds. This pressure not only reduced the pellet size, but also encouraged the glycerin to permeate the materials and form a single firm unit. It should be noted that this form of production is only used in initial laboratory experiments and actual commercial production will of course be large scale and automated.

\section{RESULTS}

The energy values for glycerin waste pellets and competing energy sources are shown in Table 1, showing that theoretically and experimentally, the glycerin waste pellet is a very suitable source in replacing or supplementing low end coal and RDFs.

Table 1: Theoretical and Experimental Calorific Values for Glycerin-Sawdust Pellets

\begin{tabular}{|c|l|c|}
\hline SI No. & Fuel Source & $\begin{array}{c}\text { Gross Calorific Value } \\
(\mathbf{k J} / \mathbf{g})\end{array}$ \\
\hline \multirow{2}{*}{1} & $\begin{array}{l}1: 1.6 \\
\text { Glycerin/Sawdust } \\
\text { Pellets } \\
\text { (Theoritical) }\end{array}$ & 17.1 \\
\hline 2 & $\begin{array}{l}1: 1.6 \\
\text { Glycerin/Sawdust } \\
\text { Pellets ( } \\
\text { Experimental) }\end{array}$ & 18.4 \\
\hline
\end{tabular}


Test method IS: 1350 (P2) was used to analyze the calorific value of Glycerin-Sawdust pellet (experimental value). The results show that pellet produced in laboratory has a calorific value on par with the theoretical value. Coal has a calorific value of $15-27 \mathrm{~kJ} / \mathrm{g}$. Hence, Glycerin-Sawdust pellets can be used in place of coal for combustion purposes.

\section{CONCLUSIONS}

Biodiesel is now an attractive alternative to regular diesel fuel because; it has a lot of advantages and benefits. Biodiesel is better than regular diesel in terms of production cost and toxic emissions. It can be produced locally and hence dependence on foreign oil is reduced. Waste cooking oil is easily available throughout the country, especially in cities and therefore it will be easier to setup biodiesel plants locally.

Reuse of glycerin from the by-product phase to make Glycerin-Sawdust combustible pellets can further aid towards the concept of zero waste biodiesel. The calorific value of Glycerin Sawdust fuel pellets (prepared in laboratory) was on par with that of the theoretical value. By combining two waste streams (sawdust and biodiesel glycerin), a new combustible fuel which can replace coal in many situations can be produced.

\section{REFERENCES}

[1] A. Ribeiro, F. Castro and J. Carvalho, (2011) "Influence of Free Fatty Acid Content in Biodiesel Production on Non-Edible Oils" in 1st International Conference Wastes: Solutions, Treatments and Opportunities, University of Minho, Braga, Portugal.

[2] A.B.M.S. Hossain and A.N. Boyce, (2009) "Biodiesel Production from Waste Sunflower Cooking Oil as an Environmental Recycling Process and Renewable Energy" in Bulgarian Journal of Agricultural Science, 15 (No 4), 312-317.

[3] Biodiesel: A Clean Alternative Fuel from Renewable Resources, Operations and Safety Bulletin (2010), A Bharat Petroleum Report, India.

[4] Ebenaza Godson. T and Vinoth. E, (2015) "Biodiesel Production from Waste Cooking Oil”, International Journal of Students' Research in Technology \&. Management., Vol 3, (8), (2015), Pg 448-450, ISSN: 2321-2543.

[5] Jose Goldenberg, (2004) "The Case for Renewable Energies", University of Sao Paulo, Brazil, February 2004.

[6] Methanol Safe Handling Manual (2008), National Biodiesel Board, USA.

[7] Sean Brady and Kawai Tam, (2008) "Zero Waste Biodiesel: Using Glycerin and Biomass to Create Renewable Energy", University of California, Riverside, Undergraduate Research Journal (V2-2008).

[8] Yun Hin Taufiq-Yap*, Nurul Fitriyah Abdullah and Mahiran Basri, (2011) "Biodiesel Production via Transesterification of Palm Oil Using NaOH/A12O3 Catalysts" in Sains Malaysia 40(6) (2011): 587-594, Department of Chemistry, Faculty of Science, Universiti Putra Malaysia. 